\title{
Modelling the uncertainty of cost and time in highway projects
}

Alireza Moghayedi PhD

Senior Research Officer, Department of Construction Economics and

Management, University of Cape Town, Cape Town, South Africa

(alireza.moghayedi@uct.ac.za)
Abimbola Windapo $\mathrm{PhD}$

Professor, Department of Construction Economics and Management, University of Cape Town, Cape Town, South Africa

The construction of highway projects is characterised by cost overruns and time delays, due to the estimation approach and inappropriate analytical tools for predicting uncertainty. This study therefore developed a hybrid intelligent tool that models three sources of uncertainty in linear infrastructure projects: variability, correlation and disruptive events. The developed tool measures the effect of uncertainties on the cost and time of projects, by combining classical and intelligence prediction techniques. The variabilities were modelled using probability distributions; the copula technique modelled the correlations. The Markov processes simulated the occurrence of disruptive events. The adaptive neuro-fuzzy inference system was used to assess the size of the impact of disruptive events on the cost and time of activities. The total project cost and time were simulated by propagating the impact of the three sources of uncertainty in the Monte Carlo simulation environment. The developed uncertainty model was validated against the final cost and time of a highway project. The study found that the accumulated impact of the three sources of uncertainty significantly increased the construction cost and time of infrastructure projects. It concludes that the improvement in the accuracy of cost and time estimation of highway projects depends on a combination of classical and intelligent prediction techniques.

Keywords: construction/cost/highway/modelling/time/uncertainty

\section{Introduction}

Highways fuel economic growth by reducing the cost of production and transport of goods and services (World Bank, 2020). These highspeed roads increase the productivity of input factors, creating indirect positive externalities and smoothing the business cycle (Ansar et al., 2016). However, the construction of highway projects has been characterised by costs exceeding budgetary limits and completion times extending further than the initial deadlines (Adam et al., 2017). The provision of accurate estimates of the cost and time required to build highways is a difficult task because highway projects are subject to risks and uncertainties, particularly in the planning phase, when very limited data and information about the project are available (Love et al., 2019). Accurate estimation of project cost and time is crucial to ensure the successful completion of a construction project (Kerzner and Kerzner, 2017). Estimating construction costs and times at the early stage of project development represents a prediction provided by the estimator, based on available information and data. This prediction is an example of a knowledgeintensive engineering task (Yuan et al., 2020) that is dependent on the expertise of the human professional. Shane et al. (2015) observed that the main problem is that the estimators' expertise is often not documented or authenticated; hence, this expertise is prone to subjectivity. Also, estimating construction cost and time to an acceptable level of accuracy is impossible to achieve manually.

There are different techniques that attempt to predict accurately the cost and time of construction projects. Accuracy and comprehensiveness in estimating cost and time are sensitive issues and can be easily influenced by various parameters. To retain a fair degree of accuracy during the estimating process, each parameter must be properly addressed (Yuan et al., 2020). Inaccurate cost estimation leads to the incorrect evaluation of projects and misallocation of scarce resources, and the result is cost escalation and delay in the total cost and time of the project. Brook (2016) studied most available estimation techniques, such as three-point, analogous, expert judgement, parametric model, published data estimation, reserve analysis, vendor-bid analysis and bottom-up, and they found that the available estimation techniques do not capture the uncertainty in the construction process of projects. These conventional cost- and time-estimating techniques provide the finest scenario estimate, which is rarely the case in practice. Therefore, it is impossible to achieve an acceptable level of accuracy when estimating construction cost and time with these classical prediction techniques.

The American Association of State Highway and Transportation Officials (Aashto) pointed out that conventional estimating approaches prepare the times and cost of construction projects with small variability. The cost and time estimates of infrastructure projects are generally prepared quickly with minimum effort because uncertainties involved in the project are not quantified, and this makes it extremely difficult to control as projects develop (Aashto, 2013).

Scholars (El Khalek et al., 2016; Mok et al., 2015; Yuan et al., 2020) are of the view that the tools and techniques developed to counteract these variables and uncertainties lack an in-depth understanding of the construction process of infrastructure projects and their concomitant uncertainties. They also hold that the current estimation tools and techniques only model risks 
without capturing the cumulative impact of different sources of uncertainty. The impossibility of conducting a cost and time estimation manually, and the uncertainty of cost and time escalation parameters, illustrates the need to establish estimation methods that appropriately capture the uncertainties in the construction process of infrastructure projects, which have an impact on the final cost and time of those projects.

Therefore, this research seeks to fill this knowledge gap by developing a hybrid intelligent uncertainty model that forecasts the cumulative impact of different sources of uncertainty (uncertainty in both the estimates and the project itself) on the cost and time of highway projects. This model is then applied to a highway construction project as a case study, to validate the developed hybrid model.

\section{Uncertainty model}

Uncertainty is an epistemic situation involving imperfect or unknown information. Apart from uncertainty due to lack of knowledge, there is uncertainty due to randomness (El Khalek et al., 2016). The main difference between uncertainty and risk is stated as being whether it is possible to measure and quantify the potential outcomes of future events mathematically through theoretical models (Knight, 2012). In the estimation of construction of highway projects, several variables are not known, since construction projects are populated by uncertainties (Zhu and Mostafavi, 2016).

According to Moghayedi and Windapo (2019), a combination of different uncertainties in the construction of linear projects impacts the cost and time of the project. They found that the cost and time of construction activity may vary from repetition to repetition, which causes the cost and time of the projects to change. Furthermore, the costs and times of construction activities are correlated, which causes the standard deviation of the total cost and time of the project to increase. It is also evident that some disruptive events occur during construction, which influence the construction cost and time of the projects. Thus, Moghayedi and Windapo (2019) determined the following three sources of uncertainties in linear infrastructure projects: variability in cost and time (the change in a variable under normal conditions e.g. how fast specific tasks can be conducted in different terrain conditions); correlation between construction costs, times and cost-time (e.g. the slow completion of one task means there will be slow completion of another task); and disruptive events (also known as unforeseen events e.g. sudden changes in the weather).

Despite the vast attention given to the cost overruns and time delays of infrastructure projects in the literature, not much improvement has been made to the accuracy and reliability of estimation of the cost and time of infrastructure projects over the years (Ahiaga-Dagbui et al., 2015). For instance, Flyvbjerg (2008) developed reference class forecasting techniques to counteract cost underestimation and time delay due to technical and psychological causes. They estimated the performance of project cost and time from an outside view rather than the inside view. The Washington State Department of Transportation (WSDOT, 2012) developed a cost estimation validation process to model risk events in construction projects by employing an impact matrix. However, very few models are available for evaluating the impact of uncertainty on construction cost and time.

In construction projects, the impact of uncertainty on the cost and time of projects has been assessed qualitatively (using contingency and impact matrix) or quantitatively (using regression modelling, probability distribution, neural network and Monte Carlo). The concept of hybrid estimating models combines the unique features of each estimating technique to capture different patterns or features in the data set. The aim is to improve the reliability of estimation by precisely assessing the uncertainty (Love and Matthews, 2020). A hybrid estimating model is particularly useful when it is not clear which model would provide more accurate estimation (Arashpour et al., 2016).

There is evidence that available hybrid estimating models improve the estimation of construction projects by quantifying the impact of variability, correlation and disruptive events in project cost and time. For instance, García de Soto et al. $(2014,2017)$ improved the accuracy of preliminary cost estimates through improved estimates of construction material quantities. They created a hybrid model using existing data, regression analysis, neural networks and casebased reasoning. Firouzi et al. (2016) developed a hybrid generic copula-based Monte Carlo model for assessing the relationships between construction costs. However, none of these estimating models is capable of modelling all sources of uncertainty and assessing their cumulative impact on construction cost and time (Moret and Einstein, 2016). Therefore, this study modelled the impact of three sources of uncertainty (variability, correlations and disruptive events) in the three main structures of highway construction - namely, earthworks, bridges and pavements. This was accomplished by integrating the classical probability estimation techniques, simulations and intelligent techniques. The developed uncertainty model was validated against the final cost and time of a real highway project. The research protocol adopted for this study is presented in Figure 1.

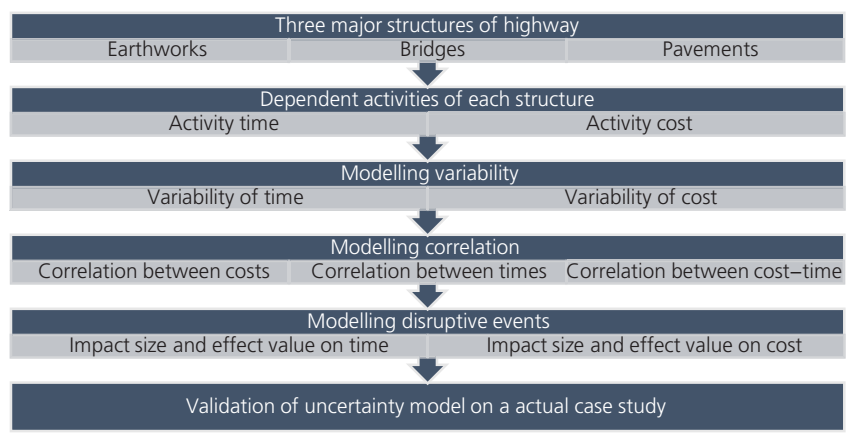

Figure 1. Research protocol of the study 


\section{Modelling of variability}

The variability is the change in a variable (cost and time) under normal conditions (Moret and Einstein, 2016). The variability in the construction process causes changes in the estimated cost and time of activities and generates a range of costs and times unless the deterministic estimation corresponds to one value (Moghayedi and Windapo, 2021). The variability in projects is quantified by defining probability distributions and the distribution parameters (Moret and Einstein, 2011).

In current research, variability was modelled with probability distributions - namely, log-normal distribution for cost and triangular distribution for time. Modelling the variability of costs and times provides the range of the possible total cost and total time by a cloud of points. This differs from the deterministic estimate of cost and time, which corresponds to only one point. The variability in the cost and the time of highway projects was modelled for each unit of the construction activities, in all three highway structures (earthworks, bridges and pavements) using the lower, most likely and higher estimated values.

From the probability distribution, one cost and time for a unit of construction activity was generated per simulation, with a Monte Carlo simulator. The number generation was repeated for every unit of construction activity until all the activities of all three structures under different geological conditions had been completed. At the end of each simulation run, the costs and the times, respectively, were summed up to calculate the total cost and the total time of the construction activity for the particular simulation run. The procedure was repeated for every simulation run until the standard deviation of the total cost and total time of activity bound within $\pm 1 \%$ in ten out of ten simulations. The total cost and the total time were the expressions of the accumulated uncertainties in the construction of all units of construction activities. Since the generated cost and time change from simulation to simulation, due to the construction process uncertainty, the cost-time scatter plot is represented by a different point for every simulation run (cloud of points).

Figure 2 presents the process of modelling variability in the construction cost and time of a highway project.

\section{Modelling of correlation}

Construction activities are influenced by different internal and external factors, such as technical, financial, political, environment, social and economic factors. When numerous activities are influenced by the same factor at the same time, their costs and times are correlated. Correlation measures and describes the strength and direction of the relationship between two variables (Benjamin and Cornell, 2014). If many activities in the project are correlated, the uncertainty of the cost and time of the project will increase (Bakhshi and Touran, 2012).

In the current study, the correlation was measured with the nonparametric Spearman correlation coefficient, and it is modelled with the Gaussian copula. These measures were chosen because they provide correlations between random numbers and a probability distribution.

Also, copula models the unit costs and production rates of the construction activities, which are correlated, and then these are summed to obtain the total cost and total time of the activities.

Bakhshi and Touran (2012) identified three types of correlation between the costs and times of construction activities - namely, correlation between the costs of activities, correlation between the times of activities and correlation between a construction cost and time. Therefore, the current study modelled the following potential correlations in the construction of highway projects: correlation between the costs/times of a repeated activity in a structure (type 1), correlation between the costs/times of different activities in a structure (type 2) and correlation between the costs and the times of an activity (type 3 ).

To model the correlation, the Gaussian copula generation and the summing of the unit costs and production rates of all activities were repeated, for each simulation run. With the copula generation, the uncertainty in each unit of construction activities was modelled, as well as the correlation between the costs and times of the activities. At the end of each simulation run, the costs and the times, respectively, were summed up to calculate the correlated total cost and total time of activities for the particular simulation run. The correlation process was repeated for every simulation run by Monte Carlo, until the standard deviation of the total cost and total time of activity bound within $\pm 1 \%$ in ten out of ten simulations. Figure 3 shows the process of modelling correlation in a highway project in this study.

\section{Modelling of disruptive events}

A disruptive event, also known as an unforeseen event, is an event with a large impact on the construction activities and process, and it occurs with some probability of occurrence, and it can severely disrupt the construction process if it occurs (Zhang et al., 2018).

Due to the rare occurrence of disruptive events and difficulty of measuring the outcome, there are, in general, no studies on the underlying impact of disruptive events on the cost and time of highway projects. The impact of disruptive events on cost and time can be assessed by modelling the probability of occurrence and severity of the uncertainty event (ISO, 2018).

According to Flyvbjerg (2014), the occurrence of disruptive events in the construction of infrastructure projects, particularly in highway projects, is higher than in the construction of other infrastructure projects, due to the unique features of highway projects. Due to the peculiar nature of uncertainty, there is a need to identify and classify disruptive events and their factors. Moghayedi and Windapo (2018) identified 76 disruptive events as affecting the construction of linear infrastructure projects under 


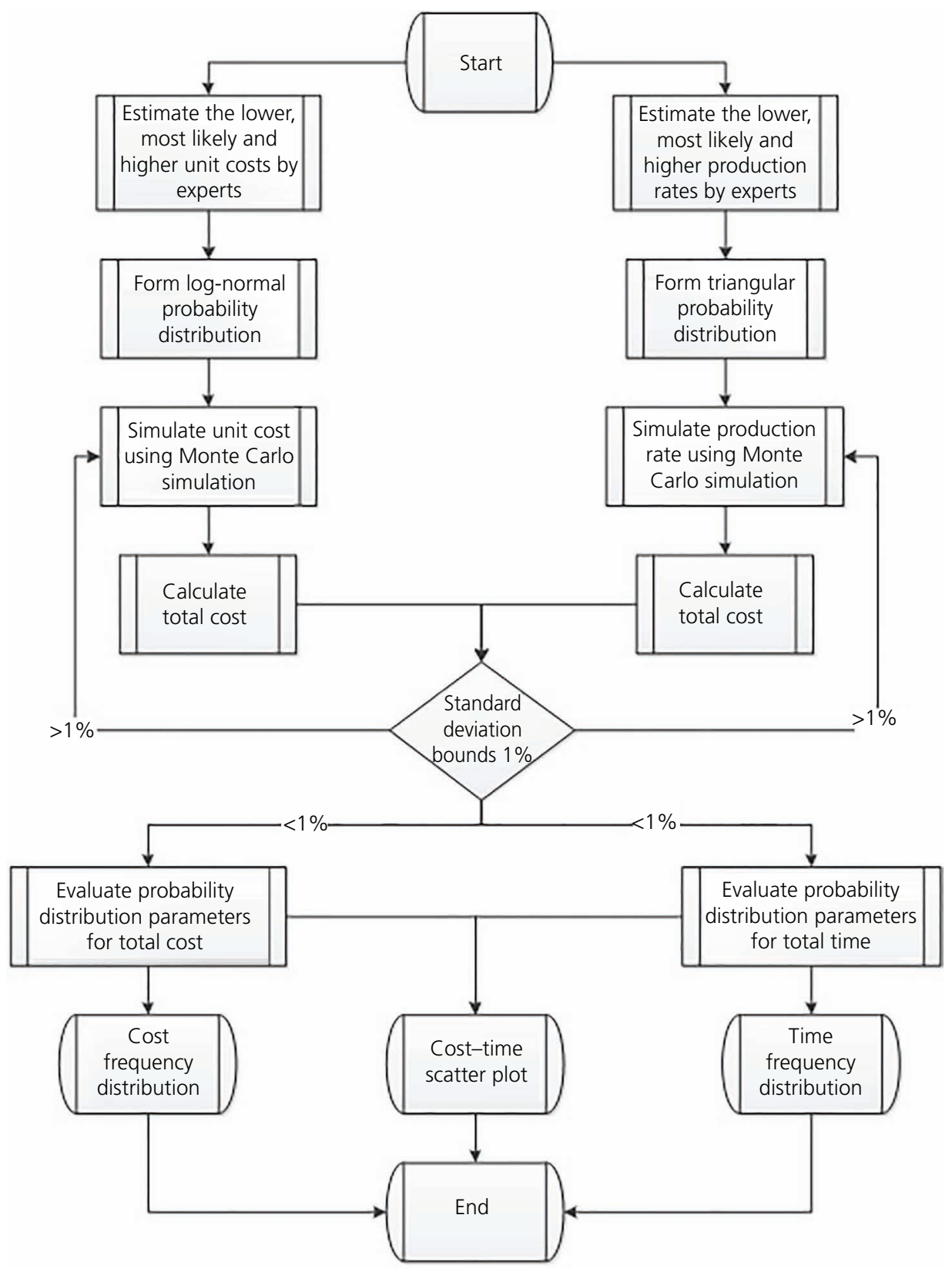

Figure 2. Modelling variability flow chart

seven major groups - namely, economic, environmental, financial, legal, political, social and technical, as presented in Figure 4. Therefore, these disruptive events were used in this study for modelling the impact of disruptive events on the construction cost and time of highway projects.

To assess the impact size of disruptive events on the construction cost and time of highway projects, the qualitative values of the probability of occurrence and severity of event were obtained from a questionnaire survey and were inserted into the ISO 31000 impact matrix as shown in Figure 5.
According to Asgari et al. (2016), quantification of disruptive events with classical methods, such as probability analysis and influence diagrams, is very difficult. Efficient applications and quantification techniques are difficult and complex, and furthermore, exact data are required (Chen and Zhang, 2014). Moreover, most classical mathematical assessment methods, such as differential equations, are not able to examine the relationship between input variables and an output variable and they are not well suited for uncertainty problems (Faizi et al., 2018). Also, these methods are based on statistical or computing techniques, and they cannot cover qualitative data that are used in the evaluation of uncertainties. The fuzzy inference system 


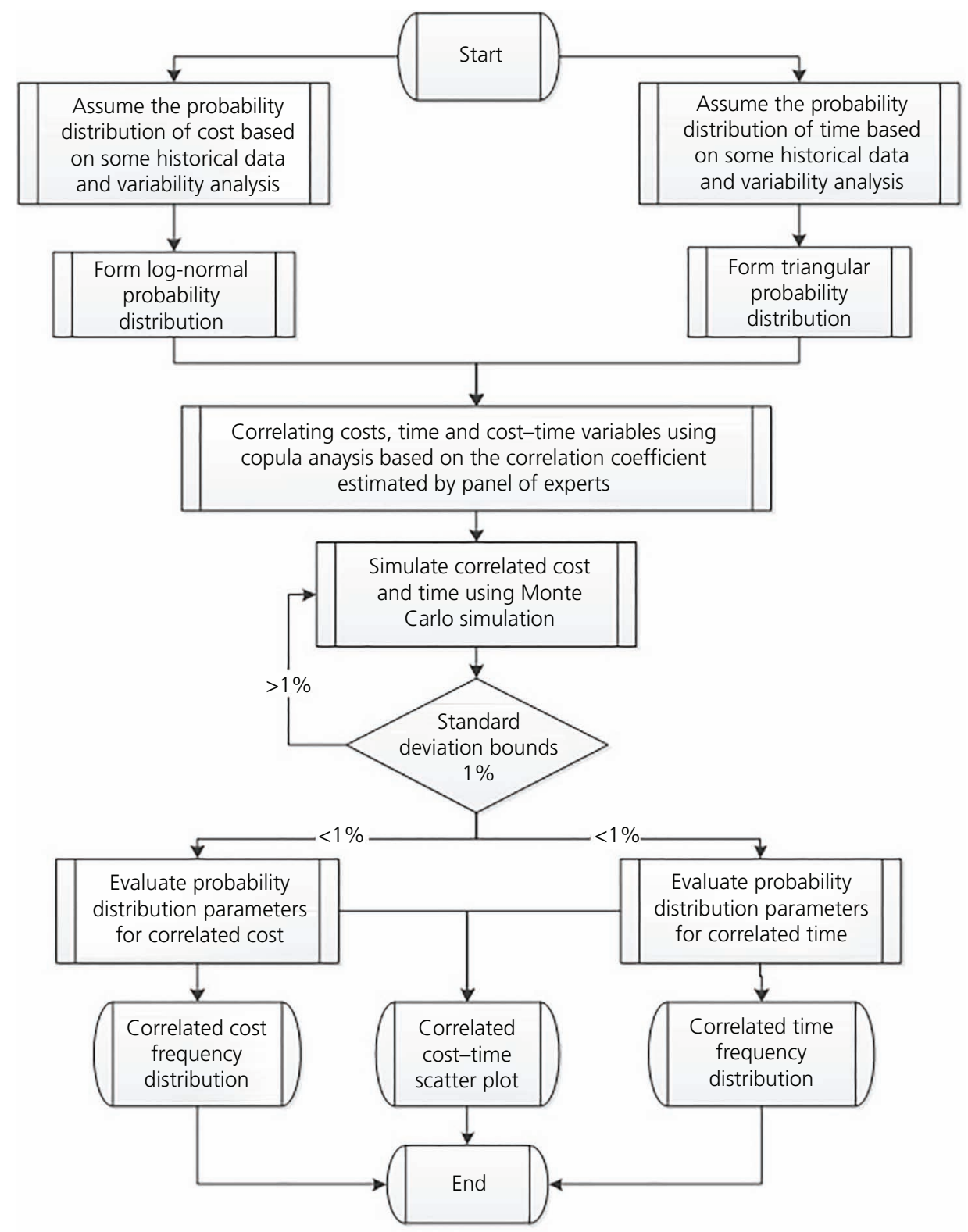

Figure 3. Modelling correlation flow chart

(FIS), on the other hand, is used in modelling the qualitative aspects without employing precise quantitative analyses. It provides standard practical methods for transformation into a rule-based system, as well as effective methods for turning membership functions for better performance index, and it is very useful in undertaking complex problems (Aengchuan and Phruksaphanrat, 2018).

The adaptive neuro-fuzzy inference system (Anfis) combines the strengths of the artificial neural network (ANN) with FISs and provides the capability to handle uncertainty, non-linearity and complex problems. It is thus an efficient method for analysing the impact of uncertainties.
Anfis goes a long way to overcome the problems that have had a marked effect on disruptive event modelling presented by the existing methods and techniques, such as classical probability techniques and analytical analysis, in that it does not solely depend on statistical and numerical data and can analyse qualitative data (Ali et al., 2018). Moreover, a shortcoming of some other methods, such as fault tree analysis and Bayesian network, is the need for high computing efforts to deal with the complexities of multiple variables or experts. This is particularly true when assessing the probabilistic relations and conditional independencies and dependencies between variables (Yazdi and Kabir, 2017). Table 1 presents both the stated advantages of the 


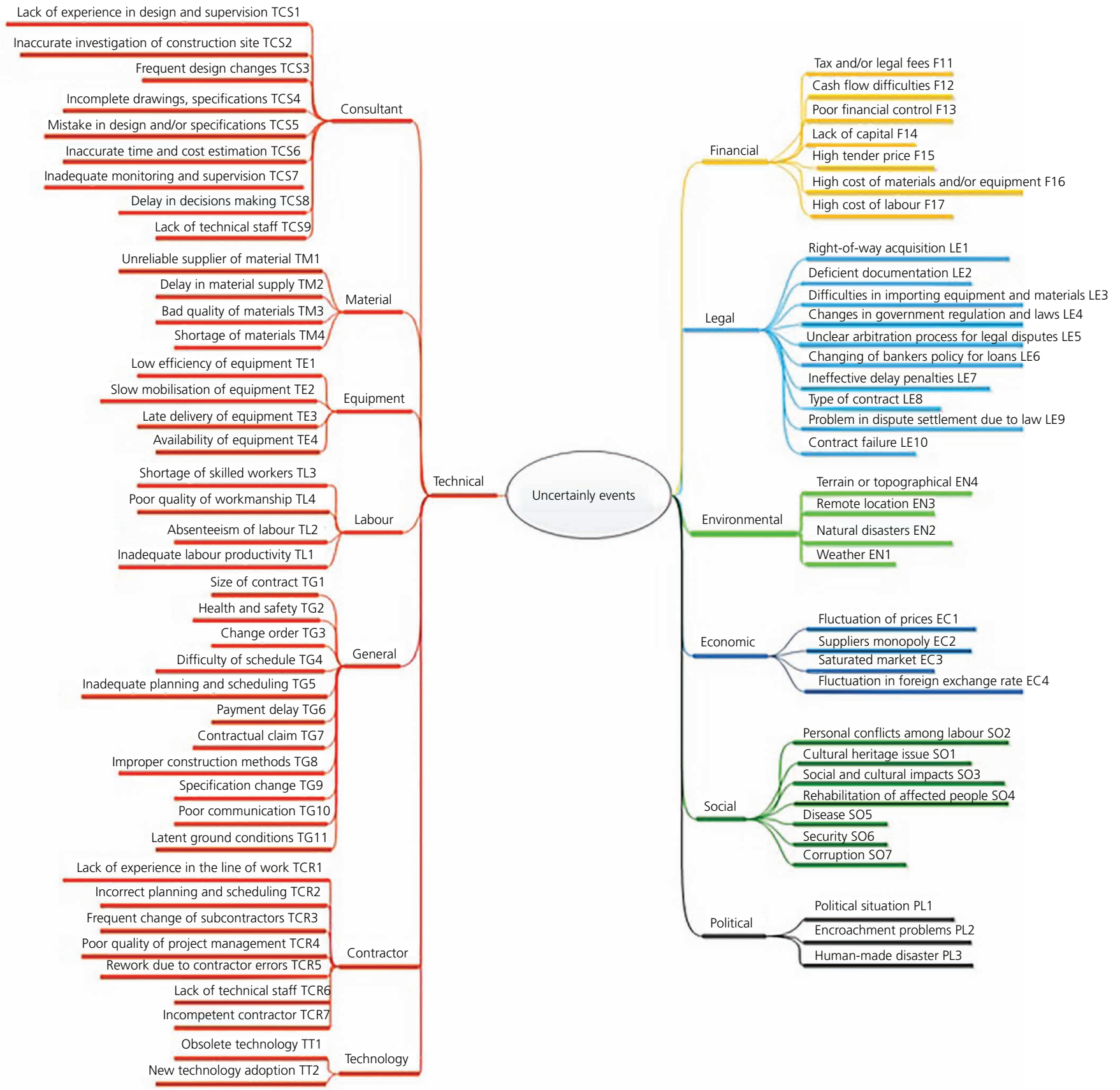

Figure 4. Disruptive events on the construction of linear infrastructure projects. Source: Moghayedi and Windapo (2018)

developed Anfis hybrid technique for predicting the impact of disruptive events on estimating the cost and time of highway projects and a summary of their comparisons with other existing methods.

Table 1 confirms that the Anfis hybrid model is a suitable technique for modelling disruptive events in infrastructure projects. This is because the Anfis hybrid model combines many advantages of all other prediction techniques. Also, it is the only model that enjoys the advantage of utilising relatively simple computing techniques and can be used for sensitivity analysis of uncertainty.

In the current study, the occurrence of a disruptive event was modelled with the Markov process, a random number generation by uniform distribution $[0,1]$ at every unit of the selected highway case study. Anfis, an intelligent machine learning technique, was used to quantify the impact sizes of the adopted 76 


\begin{tabular}{|c|c|c|c|c|c|c|}
\hline & \multicolumn{5}{|c|}{ Severity of event } \\
\hline & & $\begin{array}{c}\text { Insignificant } \\
\text { (1) }\end{array}$ & $\begin{array}{c}\text { Minor } \\
\text { (3) }\end{array}$ & $\begin{array}{c}\text { Moderate } \\
\text { (5) }\end{array}$ & $\begin{array}{l}\text { Major } \\
(7)\end{array}$ & $\begin{array}{c}\text { Catastrophic } \\
\text { (9) }\end{array}$ \\
\hline \multirow{5}{*}{ 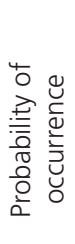 } & Rare (0.1) & Minimal & Minimal & Low & Low & Moderate \\
\hline & Unlikely (0.3) & Minimal & Low & Moderate & Moderate & High \\
\hline & Possible (0.5) & Low & Moderate & Moderate & High & High \\
\hline & Likely (0.7) & Low & Moderate & High & High & Extreme \\
\hline & Almost certain (0.9) & Moderate & High & High & Extreme & Extreme \\
\hline
\end{tabular}

Minimal: $<5 \%$ cost increase, $<2 \%$ time increase. Low: 5-10\% cost increase, $2-5 \%$ time increase. Moderate: 10-20\% cost increase, 5-10\% time increase. High: 20-40\% cost increase, $10-20 \%$ time increase. Extreme: $>40 \%$ cost increase, $>20 \%$ time increase

Figure 5. Impact matrix

Table 1. Comparison of various prediction techniques

\begin{tabular}{|c|c|c|c|c|c|c|c|}
\hline & $\begin{array}{l}\text { Probability } \\
\text { analysis }\end{array}$ & $\begin{array}{l}\text { Fault tree } \\
\text { analysis }\end{array}$ & $\begin{array}{l}\text { Bayesian } \\
\text { network }\end{array}$ & AHP & FAHP & ANN & $\begin{array}{l}\text { Anfis } \\
\text { hybrid }\end{array}$ \\
\hline Simple computing & $x$ & $x$ & $x$ & $x$ & $x$ & $x$ & $\checkmark$ \\
\hline Linearity data & $\checkmark$ & $\checkmark$ & $\checkmark$ & $\checkmark$ & $\checkmark$ & $\checkmark$ & $\checkmark$ \\
\hline Non-linearity data & $\checkmark$ & $x$ & $\checkmark$ & $x$ & $x$ & $x$ & $\checkmark$ \\
\hline Crisp data & $\checkmark$ & $\checkmark$ & $\checkmark$ & $\checkmark$ & $x$ & $\checkmark$ & $\checkmark$ \\
\hline Fuzzy value & $x$ & $x$ & $x$ & $x$ & $\checkmark$ & $x$ & $\checkmark$ \\
\hline $\begin{array}{l}\text { Learning and modelling of human } \\
\text { knowledge }\end{array}$ & $x$ & $x$ & $\checkmark$ & $x$ & $x$ & $x$ & $\checkmark$ \\
\hline Sensitivity analysis & $x$ & $x$ & $x$ & $x$ & $x$ & $\checkmark$ & $\checkmark$ \\
\hline
\end{tabular}

Sources: Omotayo et al. (2020), Ali et al. (2018), Moghayedi and Windapo (2019), Yazdi and Kabir (2017)

AHP, analytic hierarchy process; FAHP, fuzzy analytic hierarchy process

disruptive events on the cost and time of the construction activities. The magnitude of influence of the disruptive events was assessed using two variables, the probability of occurrence and severity of the event. Figure 6 presents the process of modelling disruptive events in the construction of a highway project.

\section{Application of the hybrid uncertainty model to a highway construction project}

The developed hybrid uncertainty model is applied to a $16.5 \mathrm{~km}$ section from a new highway infrastructure project, which was constructed in South Africa in 2016. This section had initial estimated total construction cost of 809504922.80 ZAR and total duration of 340 days. The construction of the project comprised: $2973692 \mathrm{~m}^{3}$ of earthworks in four different geological conditions (fine, soft, hard and rock), 46 precast concrete bridges (42 box culvert and four precast slab bridges) and $1015340 \mathrm{~m}^{3}$ of asphalt pavements.

The construction of the study highway project encountered cost overrun and time delay. The initial estimation of the cost and time taken by each structure, the cost and time of the overall highway project and then the actual construction cost and time of the project are summarised in Table 2.
As shown in Table 2, the case study project was underestimated by $43.88 \%$ on cost and $58.53 \%$ on time. According to the records of the project, the main causes of cost overrun and time delays were unseen technical and social issues, such as the changing condition of the ground, some changes in design and specifications and constraints caused by the community surrounding the project.

\section{Modelling the impact of variability}

To evaluate the impact of variability, the established deterministic total cost and total time of highway structures were compared to the 90th percentile of the developed log-normal models for cost variability and triangular models for time variability of highway structures. The three expert groups estimated the lowest possible, the highest possible and most possible unit costs and production rates of each activity, under the different geological conditions and geometric design, in their specific structure of the highway project. The 90th percentiles of the cost and time of variability models were estimated by simulating the cost and time of the activities and overall project, generated by the Monte Carlo simulation. As shown in Figure 7, the deterministic cost and time were a single value (red dot), while the results of modelling of the variability of cost and time were a cloud of values (black cloud dots). The 90th percentiles of the total cost and total time of 


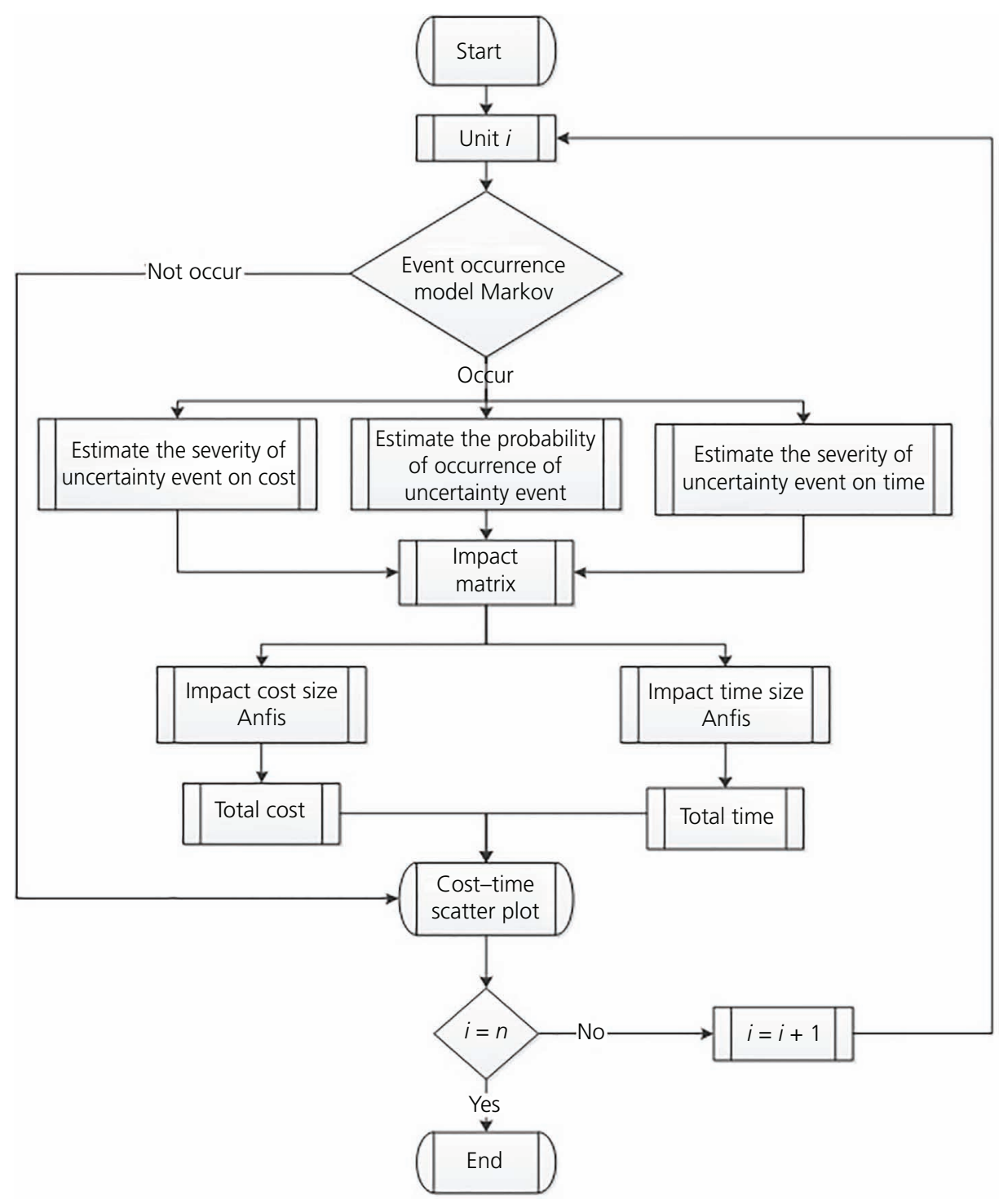

Figure 6. Flow chart for modelling of disruptive events

Table 2. Initial estimation and actual construction cost and time of study highway project

\begin{tabular}{lccccc} 
& \multicolumn{2}{c}{ Cost: ZAR } & & & Time: days \\
\cline { 2 - 3 } Structure & Initial estimation (deterministic) & Actual & & Initial estimation (deterministic) & Actual \\
\hline Earthwork & 244292292.83 & 410415938.89 & 215 & 431 \\
Bridge & 70952700.00 & 96543919.84 & 340 & 539 \\
Pavement & 494259930.00 & 657775942.64 & 217 & 320 \\
Overall project & 809504922.80 & 1164735801.37 & 340 & 539
\end{tabular}

$1 \mathrm{ZAR}=0.053 \mathrm{GBP}$ in 2016

variation models were selected to compare with the deterministic total cost and total time of the main structures of the highway project. This choice was made because the 90th percentile is located in the upper tail of both log-normal and triangular distribution models, which covers a large part of the variability distributions. It is also of note that the 90th percentile shows that there is only a $10 \%$ chance that the deterministic cost or time of structures is higher than the total cost and total time of modelled variabilities. This is assumed to be acceptable, since the 90th percentile is employed as the standard point by transportation 


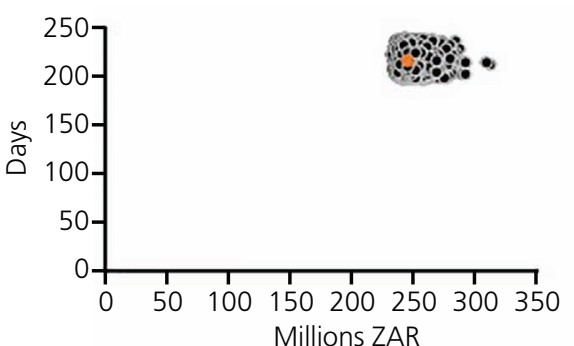

(a)

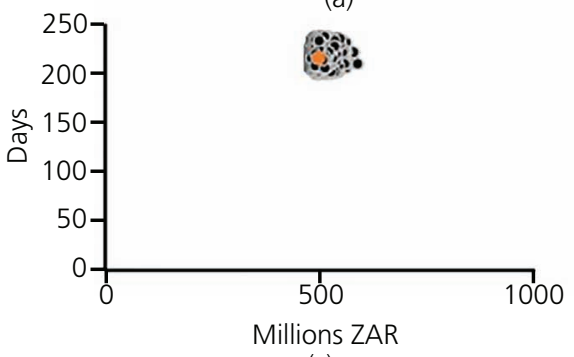

(c)

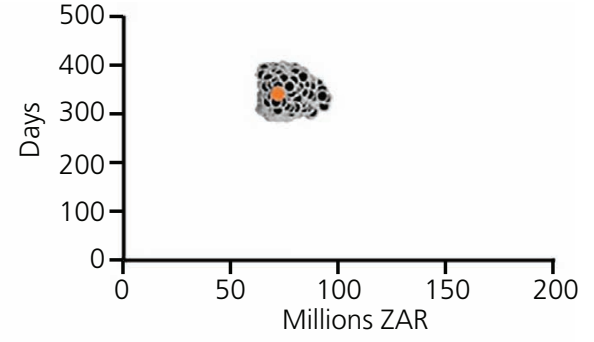

(b)

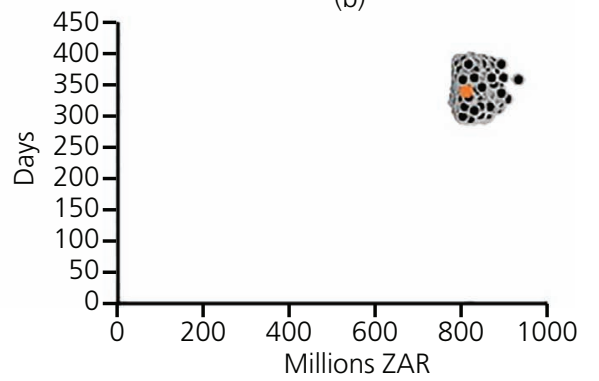

(d)

Figure 7. Deterministic cost and time and variability of cost and time for the (a) earthwork structure, (b) bridge structure, (c) pavement structure and (d) overall project

agencies worldwide, to evaluate and budget for linear infrastructure projects (WSDOT, 2018). Figures 7(a)-7(d) show, firstly, the deterministic total cost and time (red) and also the samples of Monte Carlo simulation of the variability of cost and time of the three highway structures and the overall project (black).

The cloud of values in Figure 7 proved that variability was one of the main sources of the uncertainty of cost and total time in the highway construction project. The investigation of the deterministic cost and time and estimated variation in cost and time from simulation revealed that the deterministic values of all three structures and the overall project were located in the left part of the variability cloud values since the deterministic costs were closer to the most likely cost estimated by experts (the mode is smaller than the mean in log-normal distribution).

Furthermore, the time variability models of the three structures and overall project were skewed to the right because the most likely duration for these structures and the overall project was less than the mean of the modelled variability of time. Therefore, the deterministic times are located at lower parts of the variability cloud values.
The cost variation and time variation of the three structures of the project and overall highway were calculated and are presented in Table 3.

As shown in Table 3, for all three structures and the overall project, the 90th percentiles of the cost and time distributions were larger than the relevant deterministic of cost and time (deterministic cost and time were estimated based on the mode). The variations in cost and time were the main reason for creating the cloud of values in scatter plots as shown in Figure 7. For instance, the size of this variation in the time $(8.42 \%)$ of the overall project was larger than the cost $(4.01 \%)$ dispersion. Thus, the clouds of the overall project were scattered wider along the $Y$-axis (time) compared with the $X$-axis (cost), which means the magnitude of variability in the time of the project is higher than its cost.

Further investigation of the cost dispersion and time dispersion of the three structures disclosed that the bridge structure has the highest magnitude of uncertainty among other structures at $8.36 \%$ in cost and $8.67 \%$ in time. This observation manifested that the bridge structure drives the cost and time variability uncertainty in

Table 3. Variability costs and times

\begin{tabular}{|c|c|c|c|c|c|c|}
\hline \multirow{2}{*}{ Structure } & \multicolumn{3}{|c|}{ Cost } & \multicolumn{3}{|c|}{ Time } \\
\hline & Mean & P90th & P90th: increased \% & Mean & P90th & P90th: increased \% \\
\hline Earthwork & 248195137.45 & 258410039.21 & 5.78 & 223.67 & 228.76 & 6.40 \\
\hline Bridge & 72341460.00 & 76883575.67 & 8.36 & 341.67 & 369.48 & 8.67 \\
\hline Pavement & 501019564.69 & 517582030.41 & 4.72 & 217.67 & 228.53 & 5.31 \\
\hline Overall project & 821556162.14 & 841927264.18 & 4.01 & 341.67 & 368.64 & 8.42 \\
\hline
\end{tabular}


a highway project. The practice of calculating the deterministic total cost and total time solely based on the mode (most likely) input cost and time is controversial, because the deterministic total cost and total time estimated based on the mode are smaller than the mean of possible variability modelled, due to positive skewing of both log-normal and triangular distributions. Thus, the total cost and time should be estimated based on the mean of variability ranges (Molenaar, 2010).

\section{Modelling the impact of correlation}

A probabilistic analysis was required to model the correlations on the construction cost and time of activities and to evaluate the impact of the identified three correlations on the total cost and total time of the project. Essentially, the probabilistic distribution data of the cost and time variables were not available. Therefore, to model the correlation with copula, the following marginal distribution assumptions were constructed by the panel of experts, based on the results of the variability of cost and time estimation sessions, to generate a probability distribution of costs and times.

- The minimum value of the cost and time distributions is $80 \%$ of the mode of the distribution of each variable.

- There is a probability of $2 \%$ of exceeding the high value (which is assumed to be $150 \%$ of the mode) of the cost distributions.

- The maximum of the time distributions is assumed to be $130 \%$ of the mode of the time distributions.

The 90th percentiles of the uncollated total cost and total time and the 90th percentiles of the correlated total cost and total time distributions of each highway structure were compared, to evaluate the impacts of the three identified types of correlation on the total cost and total time of each structure. Three types of correlation are shown in Table 4, reflecting the differences between the three structures and the overall project, in terms of cost and time. Table 4 provides a summary, showing the correlated estimated cost and time and the resulting means and standard deviations, as well as the variation of the standard deviations. This is the result of the process of modelling the three types of correlation to the uncorrelated case (variability, cost and time) on the total cost and total time.

Table 4 verifies that correlation between activities in a structure (type 2) is the dominant correlation that caused the largest increase in the standard deviation and 90th percentile of the total cost of all three structures and the overall project. However, the dominant correlation in the time variable depends on the arrangement of the critical activities of each structure. As shown in Table 4, the correlation between repeated activities in a structure (type 1), the correlation between activities in a structure (type 2) and the correlation between cost and time of an activity (type 3 ) are the dominant correlations that caused the largest increase in the standard deviation and 90th percentile of the total time, in the earthwork, bridge, pavement and overall project, respectively. A positive correlation causes the standard deviation of the sum of the correlated variables to increase, since cost and time correlations in construction are usually positive. Compared with the total cost and the total time when modelling only the variability, the correlated cost and time are expected to increase the range of possible total costs and total times of the project, which causes the cloud of points to expand in the total cost and total time directions.

Furthermore, the cost and time of the base case and correlation types 1, 2 and 3 of earthwork, bridge and pavement structures from Monte

Table 4. Correlation costs and times

\begin{tabular}{|c|c|c|c|c|c|c|c|}
\hline \multirow{2}{*}{ Structure } & \multirow{2}{*}{ Correlation } & \multicolumn{3}{|c|}{ Cost } & \multicolumn{3}{|c|}{ Time } \\
\hline & & Mean & P90th & P90th: increased \% & Mean & p90th & P90th: increased \% \\
\hline \multirow[t]{4}{*}{ Earthwork } & Base case & 268726606.90 & 271089094.40 & 10.97 & 222.19 & 225.59 & 4.93 \\
\hline & Type 1 & 268692562.60 & 286766429.79 & 17.39 & 222.19 & 249.18 & 15.90 \\
\hline & Type 2 & 268608078.40 & 298968508.46 & 22.38 & 222.32 & 253.63 & 17.97 \\
\hline & Type 3 & 268530325.90 & 292373016.20 & 19.68 & 222.78 & 254.45 & 18.35 \\
\hline \multirow[t]{4}{*}{ Bridge } & Base case & 78030393.34 & 80577949.52 & 13.57 & 351.35 & 357.78 & 5.23 \\
\hline & Type 1 & 78044588.91 & 85920760.74 & 21.10 & 351.36 & 396.52 & 16.62 \\
\hline & Type 2 & 78113067.80 & 86205928.64 & 21.50 & 351.46 & 392.89 & 15.56 \\
\hline & Type 3 & 78065388.98 & 86085866.87 & 21.33 & 349.72 & 381.19 & 12.12 \\
\hline \multirow[t]{4}{*}{ Pavement } & Base case & 543664957.99 & 548997579.66 & 11.07 & 224.22 & 227.62 & 4.90 \\
\hline & Type 1 & 543716702.76 & 588988971.85 & 19.17 & 224.28 & 239.00 & 10.14 \\
\hline & Type 2 & 543899815.54 & 612440433.36 & 23.91 & 224.41 & 241.64 & 11.35 \\
\hline & Type 3 & 543558761.37 & 596935711.88 & 20.77 & 224.24 & 239.16 & 10.21 \\
\hline \multirow[t]{4}{*}{ Overall project } & Base case & 821606531.66 & 896942973.77 & 10.80 & 341.54 & 357.67 & 5.20 \\
\hline & Type 1 & 889994457.90 & 939759672.15 & 16.09 & 351.45 & 395.32 & 16.27 \\
\hline & Type 2 & 889203018.70 & 962076539.65 & 18.85 & 351.23 & 392.52 & 15.45 \\
\hline & Type 3 & 892317669.00 & 949067831.41 & 17.24 & 351.23 & 381.25 & 12.13 \\
\hline
\end{tabular}

Base case: uncorrelated (variability cost and time)

Type 1: correlation between repeated activities in a structure

Type 2: correlation between activities in a structure

Type 3: correlation between cost and time of an activity 
Carlo simulations were overlaid in scatter plots and are shown in Figure 8. Correlations cause the range of the total cost and time on both sides of the mean, which is the threat of a total cost or time more substantial than the mean as well as the prospect of a total cost or time smaller than the mean total cost or time as illustrated in three overlaid scatter plots (Figures 8(a)-8(c)).

Based on the overlaid scatter plots of the three types of correlation in the different structures of the highway project (Figure 8) and the results of means, standard deviations and variation of standard deviations, it was shown that the mean of the correlated cost and time is constant across different types of correlations. This is illustrated by a constant centre of gravity in the cost and timefrequency plots. This was expected because correlations affect the standard deviation and not the mean. Furthermore, the standard deviations of the cost and total time were increased considerably from the base case (uncorrelated) to other correlation types, as shown in Table 4. The increases in total cost standard deviation and total time standard deviation are visible in the cost and time scatter plots as shown in Figure 8. In other words, the correlated cost and time are skewed to the right because the mode is smaller than the mean.

\section{Modelling the impact of disruptive events}

To identify the impact size of a disruptive event, the optimum (mean) values of the probability of occurrence and the severity of event were input to the trained Anfis rule viewers. This information about the disruptive event was obtained from the census survey. The relevant size of the impact of the event on time and cost variables was thus predicted by trained Anfis models. The effect of 76 disruptive events in the construction of linear infrastructure projects identified by Moghayedi and Windapo (2018) was simulated in this study on the cost and time of three structures of the highway project by using the Monte Carlo analysis, based on the experts' predictions of the effect value of the events. The predicted cost increase and time expansion were added to the cost and time of the structure and were utilised as input to simulate the cost and time of disruptive events. The total time and cost of highway structures were obtained from a simulated Monte Carlo analysis, equal to the volume runs of the structure. The mean, 90th percentile and standard deviation of the simulation result of each structure and overall project are summarised in Table 5.

As shown in Table 5, for all three structures and the overall project, the 90th percentiles of the cost and time were significantly larger than the relevant deterministic cost and time. Further investigation of the cost and time dispersion of the three structures disclosed that the earthwork structure has the highest impact by disruptive events at $67 \%$ in cost and $98 \%$ in time, compared with other structures. This is due to the higher probability of occurrence and severity of disruptive events in earthwork structures.

The scatter plots of the simulations of the earthwork, bridge and pavement structures and the overall highway project are plotted in Figures 9(a)-9(d), respectively.

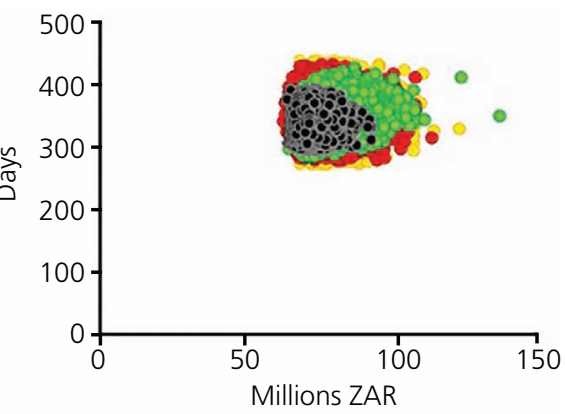

(b)

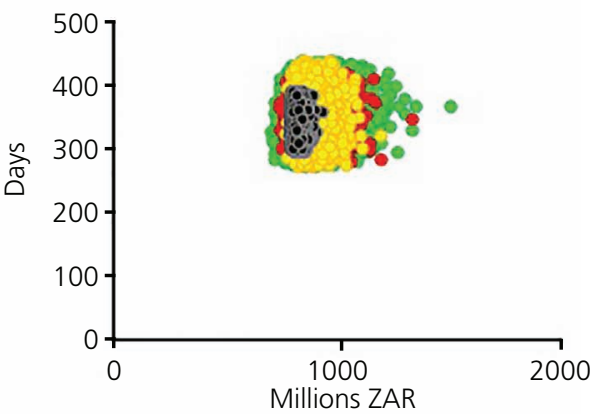

(d)

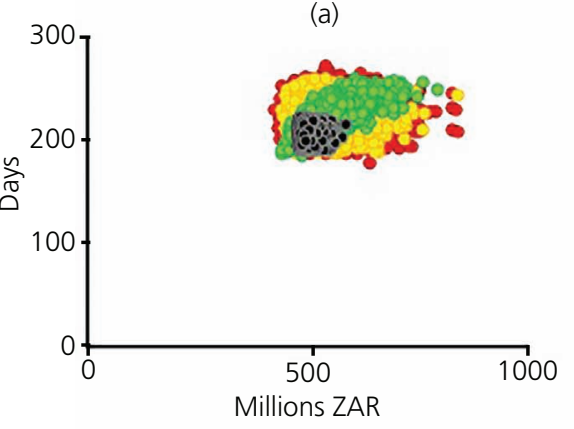

(c)

- Base case Correlation type 1 - Correlation type 2 - Correlation type 3 
Table 5. Costs and times of disruptive events

\begin{tabular}{|c|c|c|c|c|c|c|}
\hline \multirow{2}{*}{ Structure } & \multicolumn{3}{|c|}{ Cost } & \multicolumn{3}{|c|}{ Time } \\
\hline & Mean & P90th & P90th: increased \% & Mean & P90th & P90th: increased \% \\
\hline Earthwork & 354312747.94 & 407968130.11 & 67.00 & 354.12 & 425.70 & 98.00 \\
\hline Bridge & 89142843.70 & 97914726.00 & 38.00 & 474.56 & 544.00 & 60.00 \\
\hline Pavement & 630565944.98 & 667250905.50 & 35.00 & 287.74 & 323.33 & 49.00 \\
\hline Overall project & 1038796512.20 & 1154839722.87 & 42.66 & 473.85 & 544.00 & 60.00 \\
\hline
\end{tabular}

From the analysis of the simulation results of disruptive events, it was inferred that the cost and time of the structures where the disruptive event occurred were significantly larger than the time and cost of a structure where the disruptive event did not occur. The increase in the total cost and total time were visible in the scatter plots - that is, the black clouds against the red dots. Furthermore, the total cost and the total time of structures increased with different magnitudes because of the different probability occurrence models generated with the Markov process.

\section{Cumulative impacts of the uncertainty model on the construction cost and time of projects}

The increase in the total cost and total time, due to the cumulative impacts of the three sources of uncertainty in the construction of each structure of the highway project, was quantified by comparing the 90th percentiles of the total cost and total time distributions with the deterministic total cost and total time. The deterministic total cost and total time, the 90th percentiles of the total cost and total time distributions and the increases in the total cost and total time of the three structures and the overall project are summarised in Table 6.

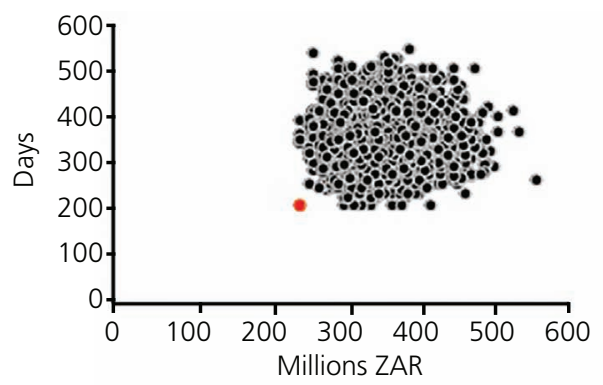

(a)

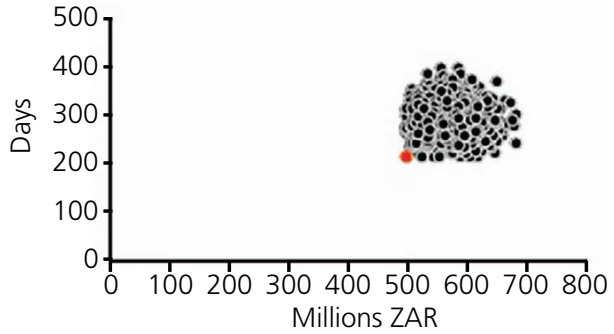

(c)
The impact of the sources of uncertainty on the total cost and total time of each structure and the overall project is shown in Figure 10.

Table 6 and Figure 10 establish that the cumulative impact of all sources of uncertainty (variability, correlations, disruptive events) caused the largest increase in the total cost and total time of the three highway structures and the overall project. For instance, the cumulative impact of the three sources of uncertainty on the total cost of the overall project was $42.66 \%$, while the impact of variability and impact of correlation on the total cost of the overall project were 4.01 and $18.85 \%$, respectively. Similarly, the cumulative impact of uncertainties on the total time of the overall project was $60 \%$, while the impacts of variability and correlation on the total time of the overall project were 8.42 and $16.27 \%$, respectively.

Further insight confirmed that the relevance of a source of uncertainty and its impact were dependent on the type of structure. The largest impact due to variability was observed on the total cost and total time of the bridge structure by 8.36 and $8.67 \%$, respectively. The largest impact due to variability and correlations was realised on the total cost of the pavement

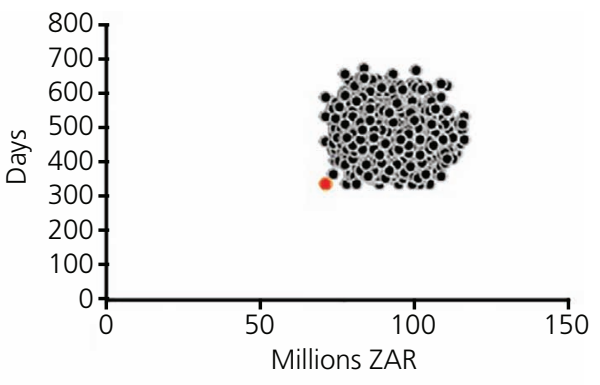

(b)

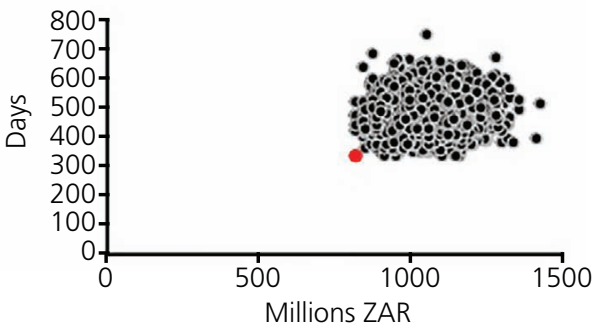

(d)

Figure 9. Deterministic and disruptive event cost and time for the (a) earthwork structure, (b) bridge structure, (c) pavement structure and (d) overall project 
Table 6. Impact of uncertainty on the construction cost and time of the case study

\begin{tabular}{|c|c|c|c|c|c|c|c|}
\hline \multirow[b]{2}{*}{ Structure } & \multirow[b]{2}{*}{ Uncertainty source } & \multicolumn{3}{|c|}{ Cost } & \multicolumn{3}{|c|}{ Time } \\
\hline & & Deterministic & P90th & $\begin{array}{c}\text { P90th: } \\
\text { increased \% }\end{array}$ & Deterministic & P90th & $\begin{array}{c}\text { P90th: } \\
\text { increased \% }\end{array}$ \\
\hline \multirow[t]{3}{*}{ Earthwork } & Variability & 244292292.83 & 258410039.21 & 5.78 & 215 & 228.76 & 6.40 \\
\hline & Variability and correlation & & 298968508.46 & 22.38 & & 254.45 & 18.35 \\
\hline & $\begin{array}{l}\text { Variability, correlation and } \\
\text { disruptive events }\end{array}$ & & 407968130.11 & 67.00 & & 425.7 & 98.00 \\
\hline \multirow[t]{3}{*}{ Bridge } & Variability & 70952700.00 & 76883575.67 & 8.36 & 340 & 369.48 & 8.67 \\
\hline & Variability and correlation & & 86205928.64 & 21.50 & & 396.52 & 16.62 \\
\hline & $\begin{array}{l}\text { Variability, correlation and } \\
\text { disruptive events }\end{array}$ & & 97914726.00 & 38.00 & & 544.00 & 60.00 \\
\hline \multirow[t]{3}{*}{ Pavement } & Variability & 494259930.00 & 517582030.41 & 4.72 & 217 & 228.53 & 5.31 \\
\hline & Variability and correlation & & 612440433.36 & 23.91 & & 241.64 & 11.35 \\
\hline & $\begin{array}{l}\text { Variability, correlation and } \\
\text { disruptive events }\end{array}$ & & 667250905.50 & 35.00 & & 323.33 & 49.00 \\
\hline \multirow{3}{*}{$\begin{array}{l}\text { Overall } \\
\text { project }\end{array}$} & Variability & 809504922.8 & 841927264.18 & 4.01 & 340 & 368.64 & 8.42 \\
\hline & Variability and correlation & & 962076539.65 & 18.85 & & 395.32 & 16.27 \\
\hline & $\begin{array}{l}\text { Variability, correlation and } \\
\text { disruptive events }\end{array}$ & & 1154839722.87 & 42.66 & & 544.00 & 60.00 \\
\hline
\end{tabular}

structure by $23.91 \%$ and the total time of the earthwork structure by $18.35 \%$. The largest cumulative impact on total cost and total time was observed on the construction of the earthwork, for which the uncertainty cost was $67 \%$ and the uncertainty time was 98\% larger than the deterministic cost and time of construction, due to the high impact of disruptive events in the earthwork structure (large number of events with a high probability of occurrence and severity in the earthwork structure).

\section{Validation of the uncertainty model}

Modelling the uncertainty of cost and time is a complex process, to which validation measures must be applied, to obtain results from probability estimation that may be analysed with a certain level of confidence. This level of confidence must represent the phenomenon of interest with a degree of accuracy consistent with the intended use of the model (Sargent, 2013).

The most reliable and preferred method of validating the forecasted results was estimating the degree of accuracy for the developed uncertainty model. The degrees of accuracy were estimated for the cost and time of each structure and the total cost and time of a project by comparing the actual cost and time with the deterministic estimated cost and time and forecasted construction cost and duration. The deterministic estimated cost and time, forecasted cost and time and observed actual construction cost and time, presented with the estimated degree of accuracy for each structure, and the total cost and total time of the overall project are summarised in Table 7.

As presented in Table 7, the degrees of accuracy of the uncertainty model in total construction cost and time (99.15 and 99.07\%) were significantly higher than the degree of accuracy of deterministic estimation (69.50 and 63.08\%).
The validation results proved that there is a significant difference between the accuracy of estimation of construction cost and time by deterministic methods and the uncertainty model. Through the validation of the developed uncertainty model, the study found that the uncertainty model improved the degrees of estimation accuracy in all three structures and the overall project. For instance, the uncertainty model improved the degree of accuracy of the cost of earthwork, bridge, pavement and overall project by $39.88,25.09,23.42$ and $31.35 \%$, respectively. These results were very close to the capital expenditure increase for road infrastructure projects $(40 \%)$ at the 90th percentile suggested by Flyvbjerg et al. (2003), as well as the estimated 90th percentile of cost escalation $(30 \%)$ in the road construction infrastructure projects. Also, the degree of accuracy of the time of the three structures and the overall project $(48.89,35.99,31.16$ and $35.99 \%$ ) were also improved when the uncertainty model was applied, which was in the middle of the range of the different time underestimations reported by Ahsan and Gunawan (2010) (55.69\%), Ngacho and Das (2014) (87\%), Kaliba et al. (2009) (86.7\%) and Moret and Einstein (2016) (23.5-94.4\%). Moreover, the margins of the error of estimation accuracy of the uncertainty model in the three structures and the overall project were within $\pm 1 \%$ (modelling conditions for stopping the simulation run of variability and correlation).

\section{Conclusions}

Using improper estimation methods and lack of understanding of the construction process and its uncertainties and modelling only risks without capturing the cumulative impact of different sources of uncertainty in the projects are the main causes of cost and time underestimations in highway construction projects. Therefore, the study examined the impacts of the variability activity, correlations 


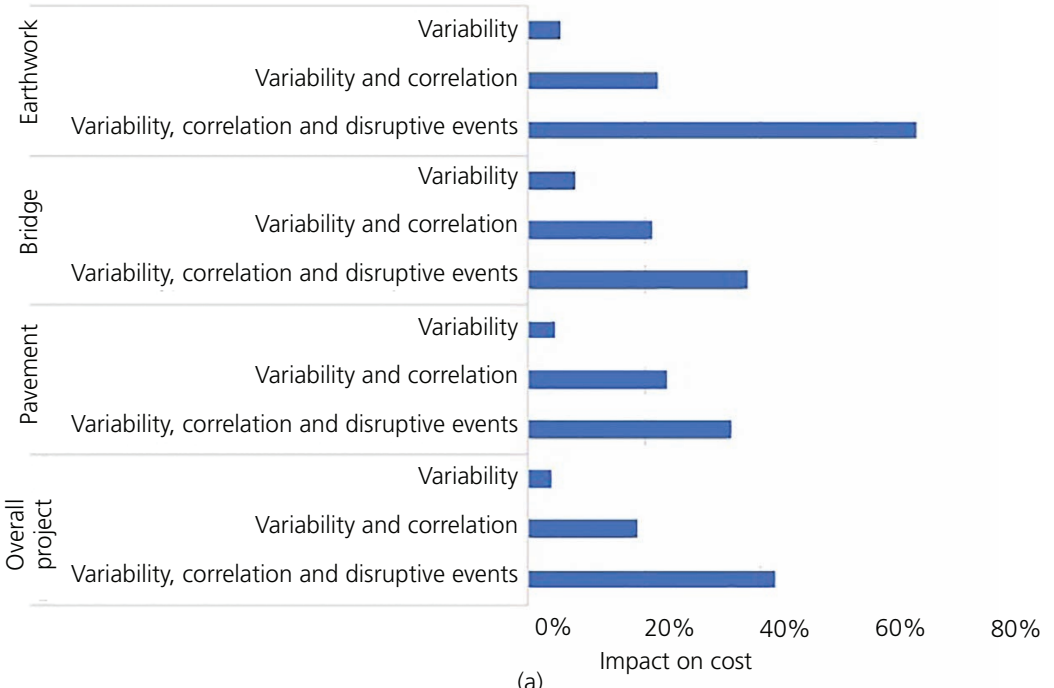

(a)

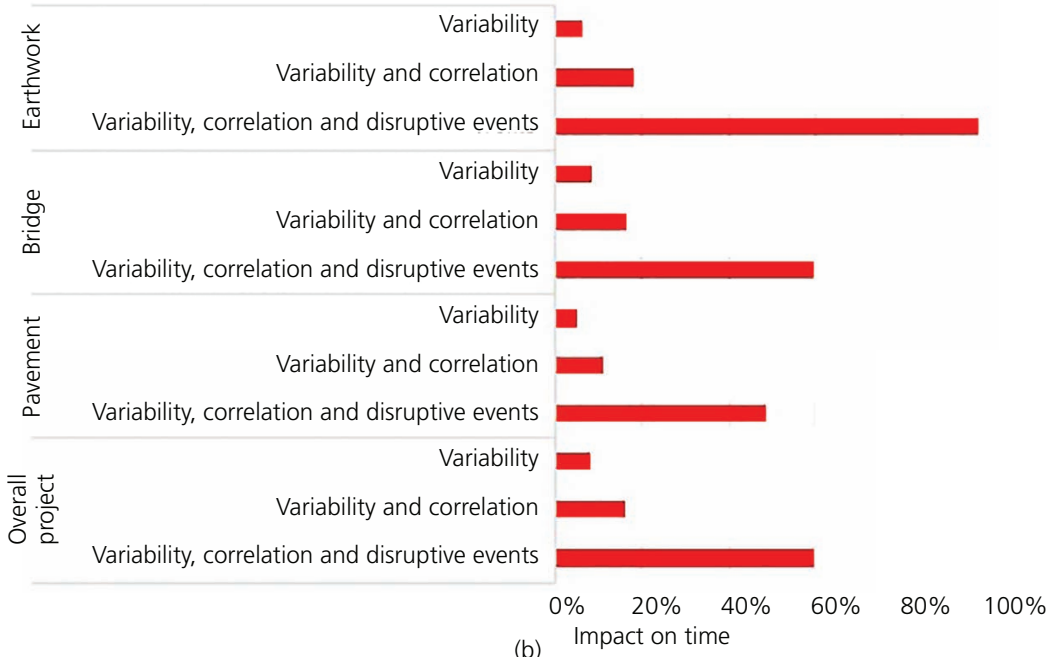

(b) Impact on time

Figure 10. Impact of the sources of uncertainty on the (a) total cost and (b) total time of the different structures and the overall construction project

Table 7. Comparison of the forecasted results with actual results

\begin{tabular}{|c|c|c|c|c|c|}
\hline & & Earthwork & Bridge & Pavement & Overall project \\
\hline \multirow[t]{2}{*}{ Deterministic estimation } & Cost & 244292292.83 & 70952700.00 & 494259930.00 & 809504922.83 \\
\hline & Time & 215 & 340 & 217 & 340 \\
\hline \multirow[t]{2}{*}{ Forecasted by the uncertainty model } & Cost & 407968130.11 & 97914726.00 & 667250905.50 & 1154839722.87 \\
\hline & Time & 425.7 & 544 & 323.3 & 544 \\
\hline \multirow[t]{2}{*}{ Actual } & Cost & 410415938.89 & 96543919.84 & 657775942.64 & 1164735801.37 \\
\hline & Time & 431 & 539 & 320 & 539 \\
\hline \multirow[t]{2}{*}{ Degree of accuracy deterministic estimation: \% } & Cost & 59.52 & 73.49 & 75.14 & 69.50 \\
\hline & Time & 49.88 & 63.08 & 67.81 & 63.08 \\
\hline \multirow[t]{2}{*}{ Degree of accuracy of the uncertainty model: \% } & Cost & 99.40 & 98.58 & 98.56 & 99.15 \\
\hline & Time & 98.77 & 99.07 & 98.97 & 99.07 \\
\hline \multirow[t]{2}{*}{ Improved degree of accuracy of the uncertainty model: \% } & Cost & 39.88 & 25.09 & 23.42 & 31.35 \\
\hline & Time & 48.89 & 35.99 & 31.16 & 35.99 \\
\hline
\end{tabular}


and disruptive events, as well as the cumulative impact of these three sources of uncertainty in the construction cost and time of highway projects, by developing a hybrid estimation method. In particular, the study developed an uncertainty model that accurately forecasted the impact of uncertainties in the three main structures of a highway project at the level of single activities and applied them to the construction of a new highway construction project.

The study developed an uncertainty model to provide a more accurate technique for estimating the cost and time of infrastructure projects. This was done by assessing the different sources of uncertainty in their construction processes. The method used by the study was to synthesise the classical probability estimation techniques and simulations and intelligent techniques. The findings from the analysis showed that there is a significant association between the project characteristics, cost and duration of highway projects. Moreover, the study concludes that the modelling of highway projects at the level of single activities is essential for identifying and forecasting the impacts of uncertainties on the construction cost and time of the projects. Furthermore, the results from the uncertainty model proved that each of the three sources of uncertainty had different impacts on the construction cost and duration of a highway project.

The research concludes that the disruptive event is the main cause of cost overruns and time delays in highway projects. In the scale of activity, the correlation between the costs of different activities in the same structure causes the largest increase in the cost of the activity, while the correlation between the times of repeated activity in the same structure causes the largest increase in the time of the activity. The cumulative impact of these three sources of uncertainty will significantly increase the construction cost and duration of infrastructure projects.

The study further deduces that forecasting the impact of different sources of uncertainty and assessing their cumulative impact on the cost and time of construction projects will significantly mitigate against underestimations in highway projects. Furthermore, the study concludes that the improvement in the reliability and accuracy of cost and time estimation of infrastructure projects depends on a combination of classical probability estimation techniques and simulations and intelligent techniques, such as machine learning. The construction model and uncertainty model should apply to other types of linear infrastructure projects, to validate the applicability of the developed intelligent hybrid uncertainty model in different types of infrastructure projects.

The developed uncertainty model based on three sources of uncertainty at the activity level provides infrastructure project planners with a hybrid dynamic tool to model and predict accurately the construction cost and time of infrastructure projects at any stage of the project. Also, the uncertainty model has three other purposes: it is the preparatory point for allocation of budget, it facilitates the update of the impact of uncertainties and it evaluates the effectiveness of countermeasures to mitigate against the threat of uncertainties.

Although the results of the uncertainty model were significant and supported theoretically, further sensitivity analysis of uncertainty model results with other prediction techniques could be considered to demonstrate the effectiveness of the developed model in capturing the impact of various sources of uncertainties on estimating the cost and duration of infrastructure projects.

\section{Acknowledgement}

This research was financially supported by the Royal Academy of Engineering, UK, under Transforming Systems through Partnership (Grant TSP 1352) and Frontiers Champions (Grant FC-2021-1-39).

\section{REFERENCES}

Aashto (American Association of State Highway and Transportation Officials) (2013) Practical Guide to Cost Estimating, 1st edn. Aashto Washington, DC, USA.

Adam A, Josephson PEB and Lindahl G (2017) Aggregation of factors causing cost overruns and time delays in large public construction projects: trends and implications. Engineering, Construction and Architectural Management 24(3): 393-406, https://doi.org/10.1108/ ECAM-09-2015-0135.

Aengchuan P and Phruksaphanrat B (2018) Comparison of fuzzy inference system (FIS), FIS with artificial neural networks (FIS + ANN) and FIS with adaptive neuro-fuzzy inference system (FIS + ANFIS) for inventory control. Journal of Intelligent Manufacturing 29(4): 905-923, https://doi.org/10.1007/s10845-015-1146-1.

Ahiaga-Dagbui D, Smith SD, Love PE and Ackermann F (2015) Spotlight on construction cost overrun research: superficial, replicative and stagnated. In Proceedings of the 31st Annual ARCOM Conference (Raidén AB and Aboagye-Nimo E (eds)). Association of Researchers in Construction Management, Reading, UK, pp. 863-872.

Ahsan K and Gunawan I (2010) Analysis of cost and schedule performance of international development projects. International Journal of Project Management 28(1): 68-78, https://doi.org/10.1016/ j.ijproman.2009.03.005.

Ali M, Deo RC, Downs NJ and Maraseni T (2018) An ensemble-ANFIS based uncertainty assessment model for forecasting multi-scalar standardized precipitation index. Atmospheric Research 207: 155-180, https://doi.org/10.1016/j.atmosres.2018.02.024.

Ansar A, Flyvbjerg B, Budzier A and Lunn D (2016) Does infrastructure investment lead to economic growth or economic fragility? Evidence from China. Oxford Review of Economic Policy 32(3): 360-390.

Arashpour M, Wakefield R, Lee E, Chan R and Hosseini MR (2016) Analysis of interacting uncertainties in on-site and off-site activities: implications for hybrid construction. International Journal of Project Management 34(7): 1393-1402, https://doi.org/10.1016/j.ijproman. 2016.02.004.

Asgari MS, Abbasi A and Alimohamadlou M (2016) Comparison of ANFIS and FAHP-FGP methods for supplier selection. Kybernetes 45(3): 474-489, https://doi.org/10.1108/K-09-2014-0195.

Bakhshi P and Touran A (2012) A method for calculating cost correlation among construction projects in a portfolio. International Journal of Architecture, Engineering and Construction 1(3): 134-141, https://doi. org/10.7492/IJAEC.2012.015.

Benjamin JR and Cornell CA (2014) Probability, Statistics, and Decision for Civil Engineers. Courier, North Chelmsford, MA, USA.

Brook M (2016) Estimating and Tendering for Construction Work. Routledge, London, UK. 
Chen CP and Zhang CY (2014) Data-intensive applications, challenges, techniques and technologies: a survey on big data. Journal of Information Sciences 275: 314-347, https://doi.org/10.1016/j.ins.2014. 01.015 .

El Khalek HA, Aziz RF and Kamel HM (2016) Risk and uncertainty assessment model in international construction projects using fuzzy logic. American Journal of Civil Engineering 4(1): 24-39, https://doi. org/10.11648/j.ajce.20160401.13.

Faizi S, Rashid T, Sałabun W, Zafar S and Wątróbski J (2018) Decision making with uncertainty using hesitant fuzzy sets. International Journal of Fuzzy Systems 20(1): 93-103, https://doi.org/10.1007/ s40815-017-0313-2.

Firouzi A, Yang W and Li CQ (2016) Prediction of total cost of construction project with dependent cost items. Journal of Construction Engineering and Management 142(12): article 04016072, https://doi.org/10.1061/ (ASCE)CO.1943-7862.0001194.

Flyvbjerg B (2014) What you should know about megaprojects and why: an overview. Project Management Journal 45(2): 6-19, https://doi. org/10.1002/pmj.21409.

Flyvbjerg B (2008) Curbing optimism bias and strategic misrepresentation in planning: reference class forecasting in practice. European Planning Studies 16(1): 3-21, https://doi.org/10.1080/09654310701747936.

Flyvbjerg B, Skamris Holm MK and Buhl SL (2003) How common and how large are cost overruns in transport infrastructure projects? Transport Reviews 23(1): 71-88, https://doi.org/10.1080/01441640309904.

García de Soto B, Adey BT and Fernando D (2014) A process for the development and evaluation of preliminary construction material quantity estimation models using backward elimination regression and neural networks. Journal of Cost Analysis and Parametrics 7(3): 180-218, https://doi.org/10.1080/1941658X.2014.984880.

García de Soto B, Adey BT and Fernando D (2017) A hybrid methodology to estimate construction material quantities at an early project phase. International Journal of Construction Management 17(3): 165-196, https://doi.org/10.1080/15623599.2016.1176727.

ISO (Institution Organizational for Standardization) (2018) ISO 31000:2018: Risk management - principles and guidelines. ISO, Geneva, Switzerland.

Kaliba C, Muya M and Mumba K (2009) Cost escalation and schedule delays in road construction projects in Zambia. International Journal of Project Management 27(5): 522-531, https://doi.org/10.1016/j. ijproman.2008.07.003.

Kerzner H and Kerzner HR (2017) Project management: a systems approach to planning, scheduling, and controlling. Wiley, Hoboken, NJ, USA.

Knight FH (2012) Risk, Uncertainty and Profit. Courier, North Chelmsford, MA, USA.

Love PE and Matthews J (2020) Quality, requisite imagination and resilience: managing risk and uncertainty in construction. Reliability Engineering \& System Safety 204: article 107172, https://doi.org/10. 1016/j.ress.2020.107172.

Love PE, Sing MC, Ika LA and Newton S (2019) The cost performance of transportation projects: the fallacy of the planning fallacy account Transportation Research Part A: Policy and Practice 122: 1-20, https://doi.org/10.1016/j.tra.2019.02.004.

Moghayedi A and Windapo A (2018) Identification of the uncertain events impacting on construction time of South African highway projects. Journal of Construction Project Management and Innovation 8(Supplement): 2146-2163.

Moghayedi A and Windapo A (2019) Key uncertainty events impacting on the completion time of highway construction projects. Frontiers of Engineering Management 6(2): 275-298, https://doi.org/10.1007/ s42524-019-0022-7.

Moghayedi A and Windapo A (2021) Modelling correlations in highway construction projects. In Collaboration and Integration in Construction, Engineering, Management and Technology (Ahmed SM, Hampton P, Azhar S and Saul AD (eds)). Springer, Cham, Switzerland, pp. 191-196.
Mok KY, Shen GQ and Yang J (2015) Stakeholder management studies in mega construction projects: a review and future directions. International Journal of Project Management 33(2): 446-457, https:// doi.org/10.1016/j.ijproman.2014.08.007.

Molenaar KR (2010) Guidebook on Risk Analysis Tools and Management Practices to Control Transportation Project Costs. Transportation Research Board, Washington, DC, USA. Report 658.

Moret $\mathrm{Y}$ and Einstein H (2011) Cost and time correlations in linear infrastructure construction. In Applications of Statistics Probability in Civil Engineering (Faber M, Koehler J and Nishijima K (eds)). CRC Press, Boca Raton, FL, USA, pp. 232-233.

Moret $Y$ and Einstein $\mathrm{HH}$ (2016) Construction cost and duration uncertainty model: application to high-speed rail line project. Journal of Construction Engineering and Management 142(10): article 05016010, https://doi.org/10.1061/(ASCE)CO.1943-7862.0001161.

Ngacho C and Das D (2014) A performance evaluation framework of development projects: an empirical study of Constituency Development Fund (CDF) construction projects in Kenya. International Journal of Project Management 32(3): 492-507, https:// doi.org/10.1016/j.ijproman.2013.07.005.

Omotayo T, Bankole A and Olubunmi Olanipekun A (2020) An artificial neural network approach to predicting most applicable post-contract cost controlling techniques in construction projects. Applied Sciences 10(15): article 5171, https://doi.org/10.3390/app10155171.

Sargent R (2013) Verification and validation of simulation models. Journal of Simulation 7(1): 12-24, https://doi.org/10.1109/WSC.2010.5679166.

Shane JS, Strong KC and Gad GM (2015) Risk-based Engineers Estimate. Minnesota Department of Transportation, St Paul, MN, USA.

World Bank (2020) Poverty and Shared Prosperity 2020: Reversals of Fortune. World Bank, Washington, DC, USA. See https://openknowledge. worldbank.org/handle/10986/34496 (accessed 19/01/2022).

WSDOT (Washington State Department of Transportation) (2012) Guidelines for CRA-CEVP Workshops. WSDOT, Olympia, WA, USA.

WSDOT (2018) Project Risk Management Guide. Department of Transportation, Washington, DC, USA

Yazdi M and Kabir S (2017) A fuzzy Bayesian network approach for risk analysis in process industries. Process Safety and Environmental Protection 111: 507-519, https://doi.org/10.1016/j.psep.2017.08.015.

Yuan T, Xiang P, Li H and Zhang L (2020) Identification of the main risks for international rail construction projects based on the effects of costestimating risks. Journal of Cleaner Production 274: article 122904, https://doi.org/10.1016/j.jclepro.2020.122904.

Zhang X, Mahadevan S, Sankararaman S and Goebel K (2018) Resiliencebased network design under uncertainty. Reliability Engineering \& System Safety 169: 364-379, https://doi.org/10.1016/j.ress.2017.09.009.

Zhu J and Mostafavi A (2016) Meta network framework for integrated performance assessment under uncertainty in construction projects. Journal of Computing in Civil Engineering 31(1): article 04016042 , https://doi.org/10.1061/(ASCE)CP.1943-5487.0000613.

\section{How can you contribute?}

To discuss this paper, please submit up to 500 words to the editor at journals@ice.org.uk. Your contribution will be forwarded to the author(s) for a reply and, if considered appropriate by the editorial board, it will be published as a discussion in a future issue of the journal. 